\title{
The impact of death and dying on the personhood of medical students: a systematic scoping review
}

Chong Yao Ho ${ }^{1,2}$, Cheryl Shumin Kow ${ }^{1,2}$, Chin Howe Joshua Chia ${ }^{1,2}$, Jia Ying Low ${ }^{1,2}$, Yong Hao Melvin Lai ${ }^{1,2}$, Sarah-Kei Lauw ${ }^{1,2}$, Ashley Ern Hui How ${ }^{2,3}$, Lorraine Hui En Tan 1,2, Xin Ling Lisa Ngiam², Natalie Pei Xin Chan 1,2, Tze Yin Joshua Kuek ${ }^{1,2}$, Nur Haidah Ahmad Kamal ${ }^{1,2}$, Jeng Long Chia ${ }^{1,2}$, Ahmad Bin Hanifah Marican Abdurrahman ${ }^{1,2}$, Min Chiam ${ }^{4}$, Yun Ting Ong ${ }^{1,2}$, Annelissa Mien Chew Chin ${ }^{5}$, Ying Pin Toh ${ }^{6,7}$, Stephen Mason ${ }^{8}$ and Lalit Kumar Radha Krishna ${ }^{1,2,4,8,9,10,11^{*}}$

\begin{abstract}
Background: The re-introduction of medical students into healthcare systems struggling with the COVID-19 pandemic raises concerns as to whether they will be supported when confronted with death and dying patients in resource-limited settings and with reduced support from senior clinicians. Better understanding of how medical students respond to death and dying will inform educationalists and clinicians on how to best support them.

Methods: We adopt Krishna's Systematic Evidence Based Approach to carry out a Systematic Scoping Review (SSR in SEBA) on the impact of death and dying on medical students. This structured search process and concurrent use of thematic and directed content analysis of data from six databases (Split Approach) enhances the transparency and reproducibility of this review.

Results: Seven thousand six hundred nineteen were identified, 149 articles reviewed and 52 articles included. The Split Approach revealed similar themes and categories that correspond to the Innate, Individual, Relational and Societal domains in the Ring Theory of Personhood.

Conclusion: Facing death and dying amongst their patients affect how medical students envisage their personhood. This underlines the need for timely, holistic and longitudinal support systems to ensure that problems faced are addressed early. To do so, there must be effective training and a structured support mechanism.
\end{abstract}

Keywords: Medical student, Dying patients, Personhood, Ring theory of personhood, Resilience, Organisational ethics, Medical schools, Undergraduate medical education

\footnotetext{
* Correspondence: Ialit.radha-krishna@liverpool.ac.uk

'Yong Loo Lin School of Medicine, National University of Singapore, 1E Kent Ridge Road, NUHS Tower Block, Level 11, Singapore 119228, Singapore

${ }^{2}$ Division of Supportive and Palliative Care, National Cancer Centre Singapore, Level 4, 11 Hospital Crescent, Singapore 169610, Singapore

Full list of author information is available at the end of the article
}

(c) The Author(s). 2020 Open Access This article is licensed under a Creative Commons Attribution 4.0 International License, which permits use, sharing, adaptation, distribution and reproduction in any medium or format, as long as you give appropriate credit to the original author(s) and the source, provide a link to the Creative Commons licence, and indicate if changes were made. The images or other third party material in this article are included in the article's Creative Commons licence, unless indicated otherwise in a credit line to the material. If material is not included in the article's Creative Commons licence and your intended use is not permitted by statutory regulation or exceeds the permitted use, you will need to obtain permission directly from the copyright holder. To view a copy of this licence, visit http://creativecommons.org/licenses/by/4.0/ The Creative Commons Public Domain Dedication waiver (http://creativecommons.org/publicdomain/zero/1.0/) applies to the data made available in this article, unless otherwise stated in a credit line to the data. 


\section{Background}

With nearly 20 million reported cases worldwide and at least 730,000 deaths [1-4], the COVID-19 global pandemic has stressed healthcare systems and impacted medical education curricula in numerous countries [5]. It is against this backdrop that medical students in certain countries are being asked to step into clinical wards and bolster primary medical teams, in some cases with minimal supervision [6-10]. For many students, this uncertain environment will likely bring with it their first exposure to death and dying. Whilst many medical schools have incorporated palliative care into their formal curricula, a prevailing culture that sees death as a medical failure still remains [11-18]. Medical educators, too, continue to struggle with sufficiently preparing their students emotionally and mentally for the caring of their dying patients and families [19-22].

In light of this pandemic, this may be exacerbated as some medical students enter a system facing "death at unprecedented rates" [23]. As senior clinicians scramble to meet clinical demands, their ability to provide support and guidance to these students are likely to fall short [24]. Ill-equipped, these medical students may be forced to witness the acute distress of multiple patients dying in isolation and watch as families grapple with physical separation from their fading loved ones [25]. Better understanding of how medical students respond to death and dying will thus inform educationalists and clinicians on how to better support them during this pandemic and beyond.

\section{The need for this paper}

A systematic scoping review (SSR) is proposed to map available data to guide the design of much needed support systems for these medical students $[18,26]$.

\section{Methods}

An SSR allows for a structured approach to systematic extraction, synthesis of actionable and applicable information and a summary of available literature across a wide range of settings [27-30]. To overcome concerns about the transparency and reproducibility of SSRs, we adopt Krishna's Systematic Evidence Based Approach (SEBA) [31-37].

Krishna's SEBA consists of five stages - the Systematic Approach, Split Approach [38, 39], Jigsaw Perspective, Funnelling and SSR in SEBA Synthesis. This process is outlined in Fig. 1.

Diversity of views and the presence of complex individual, academic, research, socio-cultural, professional and personal factors involved in understanding the impact of care of dying patients upon medical students served as the rationale for adopting SEBA as its constructivist and relativist lens allows for the mapping of complex concepts from multiple angles [40-43]. In addition, an interpretivist approach guided the research process.

In keeping with the SEBA methodology, opinions were sought at every stage from an expert team. This team comprised of medical librarians at the National University of Singapore (NUS) Yong Loo Lin School of

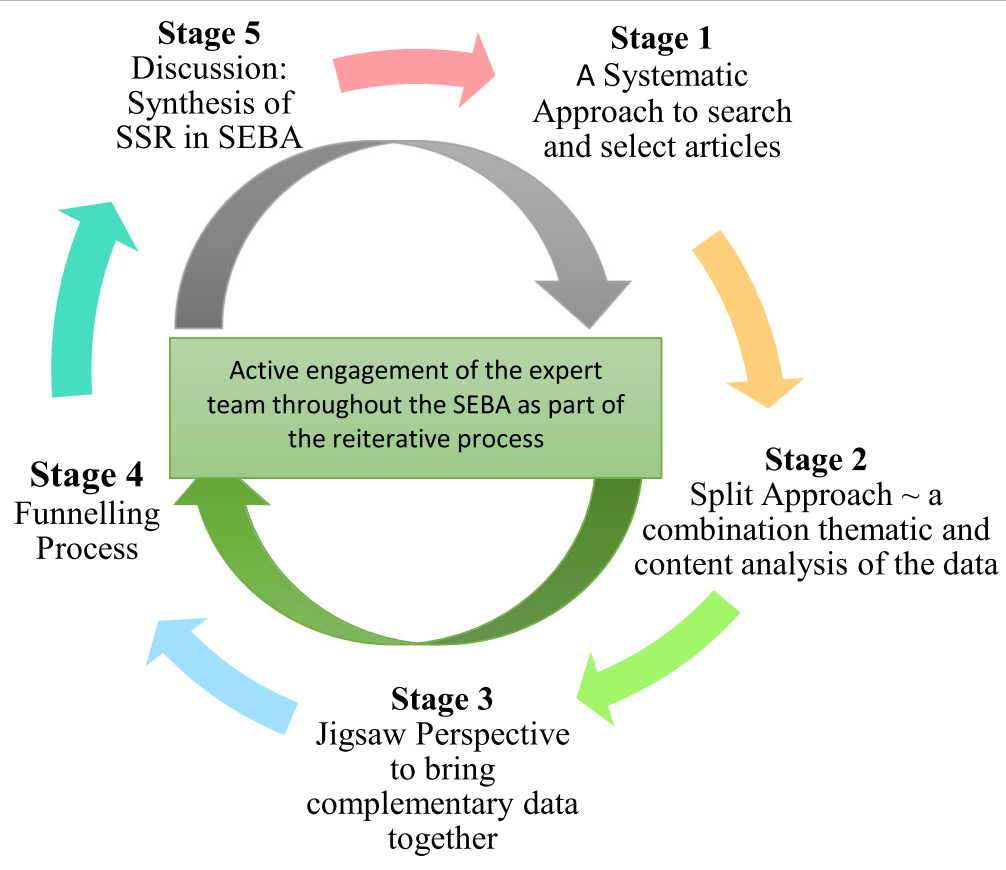

Fig. 1 The SEBA Process 
Medicine (YLLSoM) and National Cancer Centre Singapore (NCCS), as well as local educational experts and clinicians at YLLSoM, NCCS, Palliative Care Institute Liverpool and Duke-NUS Medical School.

\section{Stage 1 of SEBA: systematic approach}

\section{Determining review title and background}

Together, the research and expert teams identified the overarching goals of the SSR and ascertained the population, context and concept (PCC) to be evaluated $[44,45]$.

\section{Identifying the research question}

Designed around the PCC elements of the inclusion criteria, there was consensus amongst the two teams that the primary research question should be "How does caring for a dying patient affect the medical student - such as in their professional and personal domains and in their perception of self?" A secondary research question, "How do medical students react to exposure to dying patients?”, was also proposed.

\section{Inclusion criteria}

A PICOS format $[44,45]$ was adopted to guide the research process as shown in Table 1.

\section{Searching}

Three members of the research team carried out independent searches of six bibliographic databases (PubMed, ERIC, Embase, Psycinfo, Cochrane and Web of Science) between 17th November 2019 and 24th April 2020. Only articles published or translated into English between 1st January 2000 and 31st March 2020 were included. These parameters were established in line with Pham et al. [46]'s recommendations to ensure that the research process would be both viable and sustainable. The full PubMed Search Strategy may be found in Appendix A.

\section{Extracting and charting}

In order to narrow down the list of full-text articles for review, research team members independently reviewed the titles and abstracts identified from each database.

Table 1 PICOS

\begin{tabular}{|c|c|c|}
\hline & Inclusion criteria & Exclusion criteria \\
\hline Population & Medical students & $\begin{array}{l}\text { - Main focus on other healthcare professionals and other healthcare students } \\
\text { oDoctors } \\
\text { oNurses, nursing students } \\
\text { oAllied health workers/ healthcare support staff, allied health students } \\
\text { oOther non-medical student populations } \\
\text { - Main focus on patients/family/friends } \\
\text { oPatients } \\
\text { oCaregiver, family, relatives, friends }\end{array}$ \\
\hline Intervention/Exposure & Being involved in care of dying patients & $\begin{array}{l}\text { - No involvement in care of dying patients } \\
\text { oNo clearly defined patient care experience (e.g. study just explores student } \\
\text { attitudes to death/ palliative care) } \\
\text { oPatient population not dying patients (incl. "geriatrics", patients without } \\
\text { specification that they are dying) } \\
\text { oFocus on physician assisted suicide/ medical assistance in death/ suicide } \\
\text { oFocus on organ donation/ transplant } \\
\text { oPersonal experience of death of family/ friend } \\
\text { - Teaching activities about dying patients without substantial patient care } \\
\text { component: } \\
\text { oSimulation/ case-based learning/ hypothetical scenario } \\
\text { oDissection, prosection, cadaveric studies, autopsy } \\
\text { oOther classroom-based activity } \\
\text { oOne-off encounter with dying patient, or non-clinical encounter (e.g. half day } \\
\text { experience), as opposed to being part of care team for a substantial duration } \\
\text { - Animal studies/ Interaction with animals }\end{array}$ \\
\hline
\end{tabular}

\section{Comparison}

Outcome measures

Study design
Impact on medical students'

- Emotions

- Attitude

- Behavioural changes and adaptations

- Personal and professional development

- Personal and professional relationships

- English language

- No restriction on design (qualitative, quantitative, mixed)

- No restriction on type of publication (includes perspectives, opinion pieces, commentary, case reports, grey literature)

No restriction on geographical location of study or publication

\footnotetext{
- Main focus is evaluation and discussion of another outcome: oEffectiveness of teaching/ assessment methodology oStudent's performance/ knowledge/ skills oPatient outcomes oOthers

- Evaluation of societal norms, cultural beliefs, acceptability, ethics
}

- Non-English publications without English translation

- Unable to retrieve full article 
Sambunjak and Straus [47]'s approach to 'negotiated consensual validation' was then employed by the team to collectively arrive at a list for further consideration.

\section{Review selection}

Research team members then carried out independent reviews of these full-text articles and used 'negotiated consensual validation' once again to determine the final list of articles for analysis.

\section{Charting the data}

Two members then adopted the data charting form designed by Tan et al. [48] to organise all publications by author, year of publication, purpose of review/research question, practice setting, methodology, population characteristics and outcome evaluation.

\section{Stage 2 of SEBA: Split approach}

The research team then split into three sub-teams and simultaneously reviewed the 52 included full-text articles. The first sub-team summarised and tabulated the articles to ensure that all pertinent information was catalogued. Guidelines were drawn from Wong et al. [49]'s RAMESES publication standards: meta-narrative reviews and Popay et al. [50]'s "Guidance on the conduct of narrative synthesis in systematic reviews".

The second sub-team analysed the included articles using Braun and Clarke [51]'s approach to thematic analysis. The members independently constructed 'codes' from the 'surface' meaning of the text and located meaningful patterns [52-56] by immersing themselves in the data "without [referencing] any predetermined classification" [55]. A common coding framework was then established and refined at online and face-to-face meetings. Subthemes and themes were then developed upon collapsing the codes into larger concepts. This process yielded a list of carefully delineated themes.

In tandem, the third sub-team analysed the included articles using Hsieh and Shannon [57]'s approach to directed content analysis. This involved "identifying and operationalising a priori coding categories" [58, 59] from Baldwin et al's [60] paper entitled "Guidelines for evaluating the educational performance of medical school faculty: priming a national conversation". In keeping with deductive category application, any data not captured by these codes were assigned a new one. The coding categories were also consistently reviewed and revised where necessary. This process yielded a list of carefully delineated categories.

Finally, 'negotiated consensual validation' was used as a form of consolidation and peer debrief across all three subteams to further enhance the validity of the findings [61].

\section{SEBA's reiterative process}

As part of the reiterative process, the findings were discussed with members of the expert team. With the prevailing literature suggesting that caring for dying patients affect the very self-concept of the medical student, with ramifications on their personal and professional domains [11-18], significant consistencies were identified with Krishna and Alsuwaigh (2015)'s [62] concept of the Ring Theory of Personhood (RToP) [63-74]. As such, following discussions between the expert and research teams, the $\mathrm{RToP}$ was adopted to guide the research study.

\section{Theoretical framework}

\section{Ring theory of personhood}

The concept of personhood or "what makes you, you" put forth by Krishna and Alsuwaigh's RToP may be described in terms of four domains represented by the Innate, Individual, Relational and Societal Rings (Fig. 2).

The Innate Ring has two components - a Core and the Secondary Elements. The Core of the Innate Ring is anchored on the notion that all humans are deserving of personhood, "irrespective of clinical status, culture, creed, gender, sexual orientation, religion, or appearance", simply as a result of living and having human physical characteristics [62]. These aspects are unchanging and are retained till death. The Secondary Elements are the elements a child is born into and includes the family and community, their beliefs, values and culture. This component of the Innate Ring, unlike the Core, is alterable.

The Individual Ring is defined as the unique characteristics of a person, such as one's values, beliefs, goals, personality and character traits, as well as higher order abilities related to consciousness and cognitive function.

The Relational Ring consists of all close, important and reciprocal relationships and may include family and close friends. These ties are determined by the person and may change over time.

The Societal Ring is the outermost ring and encompasses less significant and more impersonal relationships. These include acquaintances and colleagues. Additionally, the ring encompasses societal, religious, professional and legal expectations that guide and police conduct within one's society.

In adopting the RToP as a theoretical framework amidst suggestions that witnessing death and dying would have significant impact upon the personhood of medical students, the expert team opted to carry out a second analysis of the data using Hsieh and Shannon's directed content analysis. Codes and categories were drawn from Krishna and Alsuwaigh's "Understanding the Fluid Nature of Personhood The Ring Theory of Personhood". In addition, the expert team suggested that this analysis should be carried out by a separate group of researchers to independently verify the 


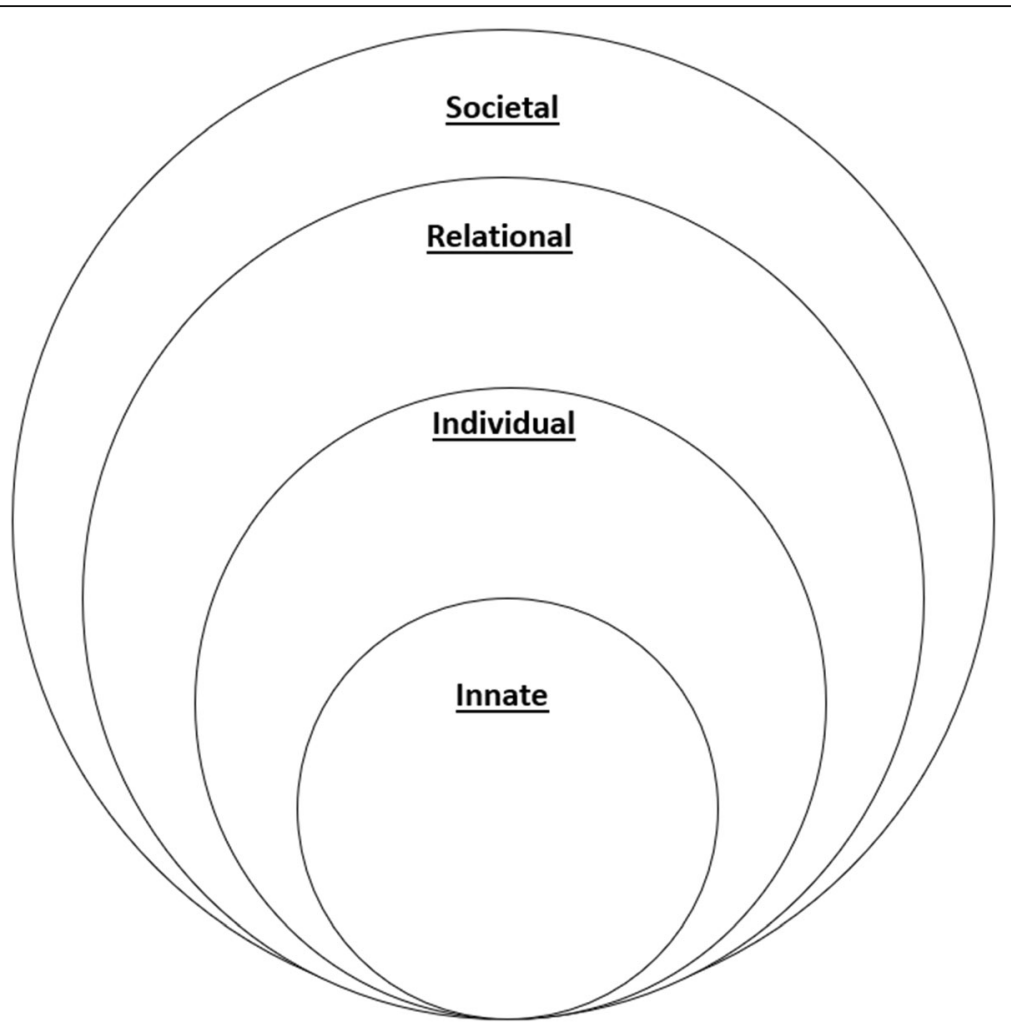

Fig. 2 The Ring Theory of Personhood

idea. As a result, five new researchers were recruited and trained to use this analytical approach.

\section{Results}

Seven thousand six hundred nineteenI abstracts were identified from six databases, 149 articles reviewed, and 52 articles (including 33 peer reviewed articles and 19 grey literature articles) were included as shown in Fig. 3 in the form of a PRISMA Flow Chart [75]. Tabulated summaries of the included articles may be found in Appendix B.

Stage 3 of SEBA: jigsaw perspective

The jigsaw perspective saw similarities between the themes and categories compared and complementary

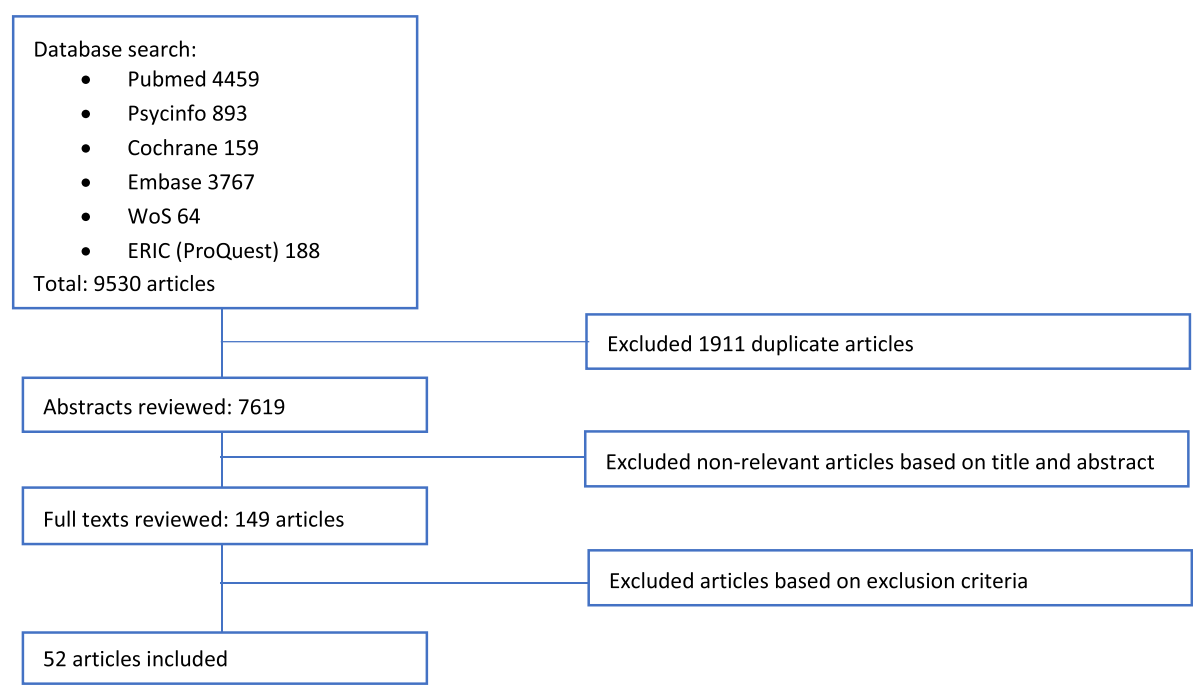

Fig. 3 PRISMA Flowchart 
elements pieced together to form a cohesive picture. It also ensured that critical aspects of the data were not lost when the Split Approach was performed.

\section{Stage 4 of SEBA: the Funnelling process}

Through 'funnelling', themes and categories delineated were compared with key insights from the tabulated summaries to further ensure a holistic picture of the data with minimal overlaps (Fig. 4).

\section{Themes and categories identified}

Scrutiny of the findings by the expert and research teams found that themes and categories from the thematic and content analysis were consistent with one another. To avoid repetition, we discuss the themes identified using both approaches in tandem. The four themes identified were the impact of death and dying on the medical students' emotional, psychological and behavioral disposition; their attitudes; their interpersonal relationships, and their personal and professional development. These themes are consistent with the RToP framework. As a result, we present our findings through the lens of the RToP, along the four rings.

\section{The innate ring}

Caring for the dying influences one's conception of life, death and religion.

\section{On life}

Many medical students recognised the transitory nature of life [76, 77] and expressed a greater appreciation of its value and the desire to make the most of it $[78,79]$.

\section{On death}

There were also personal reflections presented in the included articles on the meaning [80] and concept of death [79, 81-84]. Some reported discomfort and fear when confronted with their own mortality $[17,18,82$, $85]$ whilst others accepted death as a normal [13, 81, 86], natural part of life [13, 17, 18, 76, 79, 82, 87-89] and appreciated the notion of a "good" death [12, 14, $90,91]$. In addition, most did not see the patient's death as a failure on the part of the medical team $[14,79]$. While some developed a positive outlook $[11,18]$, some maintained an opposing stance as they viewed the role of medicine as fundamentally lifegiving and sustaining $[14,16]$.

\section{On religion}

Whilst it would be prudent not to overgeneralise such findings, one study revealed that the experience of caring for dying patients reinforced the students' religious beliefs [18] and two noted that it enabled them to find meaning in their experiences $[18,92]$. However, conflicts may arise when institutions or patients do not share their beliefs [80], as seen in Smith-Han et al. [13]'s account of medical students realising that bodies were not always treated as sacred in clinical institutions.

\section{The individual ring}

The impact of death and dying on the Individual Ring may be perceived in how medical students think, feel and act from both a personal and professional standpoint.

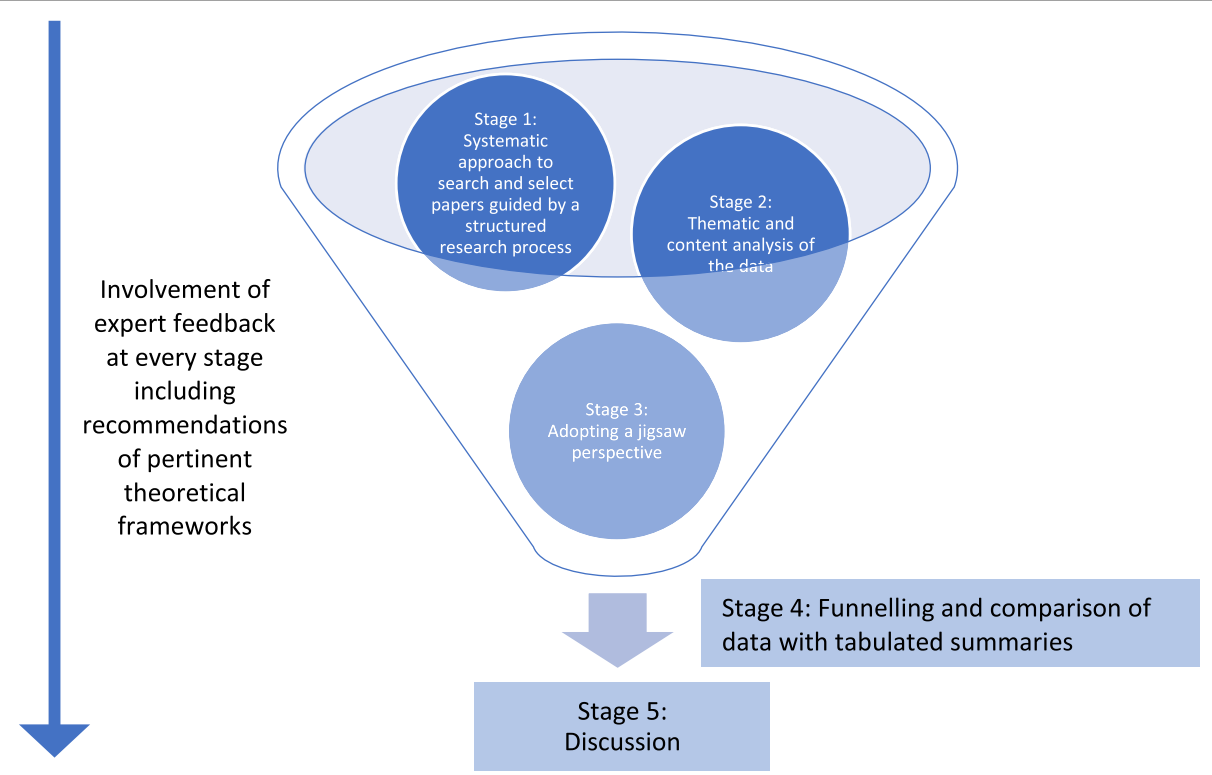

Fig. 4 Novel structured approach to SSR 


\section{Personal}

Memorable, powerful, inspiring and transformative [16, $78,81,85,86,93,94$ ] were some of the descriptors used by medical students when asked to describe their first experience with a patient's death. For some, caring for the dying was a satisfying experience $[16,17,88]$ with some feeling moved [17, 92, 94], humbled and grateful for the opportunity [92, 94-97]. Some students felt more comfortable discussing death and dying after these personal encounters $[78,80,86,91]$. They also reported being better able to manage their emotions and cope [1113, 21, 84, 89, 94, 98, 99]. Indeed, two studies reported improvements in the medical students' management of sadness, hopelessness, and helplessness [18, 100]. Positive coping strategies such as reflective writing [77, 79, $80,84,85,94,99,101,102]$ were often used to help regulate their emotions [13, 21, 99, 102]. Others sought comfort by partaking in religious rituals or prayer [12, $14,18,99]$, exercise or hobbies $[12,13]$ or simply by taking time off work $[14,101]$.

These close interactions taught medical students important lessons on the power of listening [17] and "bearing witness to another's suffering" [100]. One article found that it instilled humility in the students [103] and encouraged them to reflect on their values [85, 87, 92]. Those who cared for the dying during medical school were also found to have a more positive attitude towards these patients [11, 104], with a greater sense of relief, peace and acceptance of their abilities and limitations $[76,78,85,105]$. This may in turn minimise rates of compassion fatigue and burnout [94]. Two studies reported that students developed a greater interest in their patients' holistic medical, psychosocial and spiritual well-being $[18,100]$.

However, some medical students found themselves breaking into tears $[13,14,21,76,77,81,84,87,94,98$, $99,101,106]$ and others fighting back their own emotions [81, 84, 102]. Some withdrew by physically stepping away from the situation [87, 94] or isolating themselves [77]. One student defaulted to the reciting of medical protocol while others described "freezing up" $[16,22,79,87]$. Shortly after their encounter, some medicals students described being in a complete daze [79, 103] or preoccupied with lingering thoughts of the patient [21]. Some expressed their initial denial [18, 77, 99] and envisaged a different outcome [79] while others tried to rationalise their thoughts away $[87,106]$. For some, sleep eluded them [21]. For others, vivid imagery and flashbacks $[16,18,21,87,107]$ incited feelings of distress and persisted for a significant duration after the encounter.

Often, shock [12, 13, 16, 21, 22, 87, 99, 101, 108], confusion and conflict $[21,22,77,79,80,85,101-103,109]$ were also experienced by the medical students. Being unable to find the "right words" to verbalise their feelings left many "traumatised" $[14,16,18,78]$ and emotionally overwhelmed [18, 21, 81, 84, 85, 87, 92, 98]. In one article, Slim [79] narrated his struggle of reconciling his patient's "Do-Not-Resuscitate" order with his own desire to "do no harm". Medical students also reportedly experienced sadness and grief $[12,16,21,77,78,84,87$, $92,101,105,107,110]$, guilt $[11-14,16,18,21,77,78$, $87,98,101,105]$, anger and frustration $[14,18,21,84$, $87,90,92,101,104]$, a sense of injustice $[18,90,101]$ and helplessness at being unable to change their patient's outcome [18, 21, 22, 78, 81, 92, 97, 99, 104]. A minority described experiencing physical reactions such as throat tightness [76] and paresthesia [21] in the wake of their patient's death.

\section{Professional}

When armoured with experience, some medical students described feeling more comfortable [12, 83, 91, 111], confident and prepared for managing their dying patients $[12,16,17,80,85,86,89,92,97,110,112]$ and better understood the responsibilities involved in processing the formalities of death [13, 87]. Many developed a deeper appreciation of the impact of death and dying on patients and their families $[78,80,84,93,96]$ and the need for the former's $[17,85,88,93,95,96,98,99,104]$ and latter's holistic care [21, 92, 103]. Students also began to more consciously view their patients as fellow persons instead of apprehending them by their disease $[17,78,81,84,85,92,98-100,103]$.

These experiences assisted in their professional identity formation as well $[12,13,109]$. Students were given the opportunity to hone their communication skills [78, $83,85,86,93,96,100,104,113-115]$ which led to newfound self-confidence in their clinical role [99]. Witnessing a patient's death allowed some students to develop greater empathy and sensitivity towards the dying [82, 113]. As opposed to their previous uncertainty and anxiety, some were more self-assured as to what empathetic practice meant [84]. Crawford and Zambrano [89] observed that junior doctors trained earlier in palliative care had enhanced levels of professionalism, communication, teamwork, self-awareness and skills in patientcentered medicine - including attunement to their psychosocial and spiritual needs. Students who cared for dying patients during medical school were also found to have higher knowledge scores on end-of-life care issues [81, 104].

Yet, some medical students also reported suppressing their feelings and detaching themselves emotionally [13, $18,21,92,99,106]$ especially in front of their superiors [14]. Over time, they began to "medicalise" their thoughts on death and became increasingly desensitised to the profound humanity of their patients $[18,99]$. 


\section{The relational ring}

In several medical students, caring for dying patients triggered memories of personal bereavement $[16,21,84,87$, 106]. Strong emotions were particularly evoked when the patient belonged to a similar age group to their loved ones $[12,16,21,82,84,87,116]$. As a means of coping with these emotional challenges [12, 16, 21, 86, 89, 98], a number of medical students relied on their own family members for support [12-14, 16, 18, 21, 79, 84, 86, 90, 98, 101].

\section{The societal ring}

The experience of death and dying had varied effects on the relationship medical students had with members of their Societal Ring - these include their patients and loved ones as well as other healthcare professionals and the profession itself. Broadly, the effect may be classified as either weakening or strengthening.

\section{Relationship with patients}

- Weakening: Some medical students faced difficulty understanding their patients' perspectives and feelings [84, 95]. Others felt awkward interacting with the dying $[22,80,85,117]$ and were uncertain about their role when doing so [107].

- Strengthening: Conversely, some felt that the experience allowed them to better understand the needs of their dying patients [77, 78, 84, 95, 96, 103]. They learnt how to better listen and provide support [12, 14, 17, 84, 97, 99, 100], honed their soft skills in communication $[95,116]$ and developed virtues such as patience [17] and compassion [82]. Many built rapport, developed attachments [12, 14, $76,80,98]$ and were inspired by their patients' and their own experiences $[86,94,108]$.

\section{Relationship with patients' loved ones}

- Weakening: Some medical students found it emotionally challenging and stressful to interact with their patients' loved ones [14, 18, 21, 118], especially if it involved breaking bad news [18] as they dreaded having to deal with the emotional anguish [110]. Pessagno et al. [14] noted that some were also worried about potential litigation issues. At times, the students struggled to reconcile incongruences with their patient's wishes, that of their loved ones and professional medical opinion their best interests $[79,106]$. Some felt pressured to accede to their family's demands [106].

- Strengthening: While caring for their patients, medical students also learnt to communicate sensitively and build rapport with their patients' loved ones [12, 21, 93, 95, 98]. They learnt the importance of showing empathy and supporting the family through the process $[12,17,21,80,95,98$, $99,107]$ and some also journeyed together with them through prayer $[98,99]$.

\section{Relationship with other healthcare professionals and the profession}

Individual studies attributed the varied effects on medical student-clinician relationships to different levels of emotional sensitivity and personalities of the clinicians [102], different care settings - emergency department versus inpatient service [21] - and cultural or societal norms in different countries [102].

- Weakening: Many medical students struggled with a lack of support and guidance from their seniors and faculty $[16,22,87,101,102,107]$. Some did not feel comfortable approaching their superiors for help. Diverse reasons include the fear of being burdensome [101, 107], their feelings of awkwardness [79], the desire to appear professional [14], the medical team's insensitivity or lack of emotion $[16,21]$ and their disagreement with advice proffered by their seniors to simply desensitise themselves to death [77, 102]. Others felt disempowered and discouraged from actively participating in the care of the patient [12, 99, 102]. Such experiences may have contributed to their belief that their educational needs were not adequately met [16].

- Strengthening: However, some medical students found comfort in discussing their experiences and emotions with other senior clinicians [12-14, 16, 90, 99, 102]. Some were impressed and regarded their seniors as good role models to emulate their behaviour on $[12,17,21,82,84-96,99,102,113$, $118]$ and were able to built strong positive relationships with them $[12-14,84,86,90,98,99$, 102].

- On palliative care and the role of doctors: Medical students became more aware of the value of palliative care and adopted positive attitudes towards it [11, 101]. Baumrucker and Woods [96] reported that medical students felt more comfortable referring their patients with terminal illnesses to hospices. Kearsley and Lobb [84] found that prior negative impressions of palliative care were positively altered. This may be attributed to their broadened understanding of what it means to be a physician - from trying to "cheat death" and prolong life, to preserving their patient's quality of life and helping them transition towards a more dignified death [13, 17, 92]. Perceptions of the doctor as a life-saving hero was altered to one 
centred on showing care through the effective management of illness [13] and the provision of bereavement aid [11, 111]. Individual studies reported that through these experiences, medical students acknowledged the limitations of medical intervention [14] and recognised that non-medical acts such as providing a listening ear or a warm embrace may provide much needed healing for the dying patient [76].

\section{Stage 5 of SEBA: synthesis of SSR in SEBA}

The SSR produced was guided by the Best Evidence Medical Education (BEME) Collaboration guide [119] and the STORIES (Structured approach to the Reporting In healthcare education of Evidence Synthesis) statement [120]. In addition, two members of the research team employed the Medical Education Research Study Quality Instrument (MERSQI) [121] and the Consolidated Criteria for Reporting Qualitative Studies (COREQ) [122] to evaluate the quality of quantitative and qualitative studies included in this review respectively (Appendix B).

\section{Discussion}

In mapping how medical students are affected by their exposure to death and dying, this SSR in SEBA highlights the advantage of using $\mathrm{RToP}$ as a wider framework to analyse these findings.

\section{Implications of the entwined rings of personhood The entwined nature of the rings of the RTOP}

The four rings of personhood do not stand in isolation to one another but are dynamically entwined as originally put forth by Krishna and Alsuwaigh. Whilst the Societal Ring is traditionally seen as a means of ensuring that basic standards of practice, etiquette, rights and codes of conduct are adhered to, senior clinicians have an immediate effect on how the medical student thinks, feels and behaves through the provision of timely personalised advice and feedback, role-modelling, support for their professional identity formation, active facilitation of their continuous learning, guidance in the development of their self-efficacy in caring for the dying, and by helping them develop better methods of coping in the face of their patients' demise $[77,79,80,84,85,90,94,99$, 102]. These may be best understood as 'organisational influences' which are intrinsic to the medical program's culture and structure. Well-supported students are inclined to see these trying experiences as transformative $[76,78,85,105]$ and affirmative of their career choices.

\section{Building resilience}

Such experiences underscore the impact of positive and congruent experiences on building one's resilience. This highlights a further feature of the RToP, that experiences in one ring may strengthens the others. For example, societal and familial support and religious beliefs that positively impact the Societal, Relational and Innate Rings also bolster the Individual Ring. This helps to build resilience in medical students and boost their self-assurance.

When medical students face challenges in their line of work, significant family and friends from the Relational Ring may serve as a prominent source of encouragement, allowing for their reprieve and reinvigoration [12, 21, 84, 87, 116]. Similarly, the reevaluation and reinforcement of their religious and spiritual values within the Innate Ring may allow students to derive meaning from and make meaning of their bleak experiences $[13,17,18,76,79,82,87-89]$.

\section{'Dyssynchrony'}

Conversely, evidence of their entwined nature provides a unique opportunity to observe how caring for the dead and dying may result in conflicts or 'dyssynchrony' between the rings of personhood. This may arise when changes in one ring run against convictions, values or practices held in another ring (Fig. 5).

Dissonance have been reported between the medical student's:

\section{Individual and Societal Rings.}

- personal beliefs, expression of feelings and expectations that a professional should remain detached and emotionally distant towards patients $[13,16,84,101,102,107]$.

- personal values of honesty and the professional ideal of diplomacy and sensitivity [116].

- personal, religious and/or moral duty to save and prolong lives which are "at odds" with the patient's wishes and professional obligations to respect "DoNot-Resuscitate" orders [79].

\section{Innate and Societal Rings.}

- innate or cultural view that death is a failure and the patient's subsequent death $[16,79]$.

- innate view that "young deaths" are unnatural and their occurrence in reality $[14,18,87]$.

- religious beliefs about the sanctity of the human body and the attitude adopted towards bodies in hospitals [13].

The ramifications of unresolved 'dyssynchrony' between two or more rings may exacerbate and prolong feelings of moral distress and confusion in medical students $[18,89]$. Risking potential compromise of their responsibilities as healthcare providers, these feelings may 


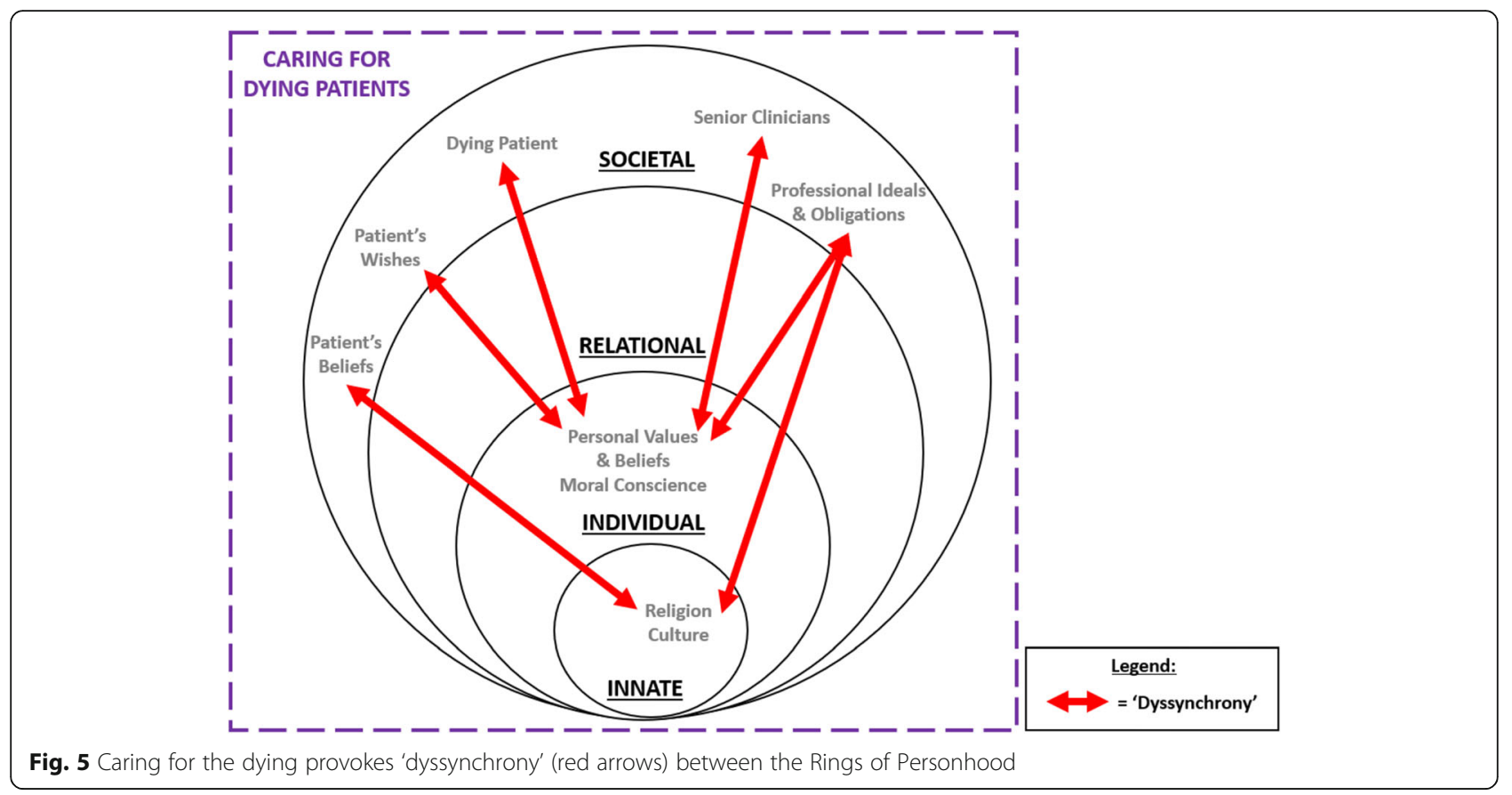

manifest in the form of guilt [18], anger [18, 89], feelings of incompetence $[16,18]$ and in questioning their "purpose of being a doctor" [18].

In addition, medical students may be conflicted between their obligations to the safety of their families and their duty to augment healthcare workforces in the face of the COVID-19 pandemic [123-128]. The personal and professional desire to always 'do no harm' is also compromised amidst reports of feeling overwhelmed and exhausted by the increased workload and shortage of personal protective equipment (PPE) [129, 130].

Higher volumes of dying patients also intensify the dyssynchrony between their aspiration to save lives and their forced reality to let die. Students may find themselves entangled in "emotionally and ethically fraught resource-allocation decisions" [24] due to the utilitarian shift away from individual choice and autonomy, and towards "saving as many lives" [131].

These situations are further exacerbated by the act of being thrust into a "completely new context" with the new environment in the isolation wards bringing with them "a sense of oppression" [130]. Restrictions placed on religious congregational services, limited access to usual support systems [132-135], and the discontinuation of death rituals as a result of safe distancing measures may lead to disenfranchised grief, with little time and space to resolve this 'dyssynchrony'. It could be surmised from the SARS epidemic $[136,137]$ that such unresolved 'dyssynchrony' across the various domains of personhood may result in higher rates of psychiatric morbidity, burnout and post-traumatic stress (PTS)
[133-135]. The dyssynchronous effects of COVID-19 across the various rings and the disruptions they bring are presented in Fig. 6.

\section{Supportive interventions in medical school curriculum}

Evidence of adverse clinical, psycho-emotional, spiritual and personal repercussions underlines the need to consider organizational strategies to manage these risks. While medical students have a potential role in alleviating manpower shortages, this must be weighed against other important considerations such as their physical and emotional well-being, which institutions have a duty to ensure, as well as their potential threat and actual benefit to the system. Their manifold likelihood of carrying and transmitting the virus may "introduce unnecessary risks for patients and other clinicians" and the activation of these students may consume already strained supplies of PPE [104]. Should the organisation be unable to provide adequate support to the medical students and address these concerns, it would not be ethically justifiable to involve them in patient care during this period.

In light of these and drawing from lessons learnt in 'peace time', we proffer suggestions as to how to address the needs of medical students entering and/or returning to clinical care. A phased return to clinical practice is crucial. This will provide educators with the opportunity to establish an ethics team to guide difficult ethical decision-making, train senior clinicians to mentor more effectively, identify at-risk students, facilitate their professional identity formation, offer 

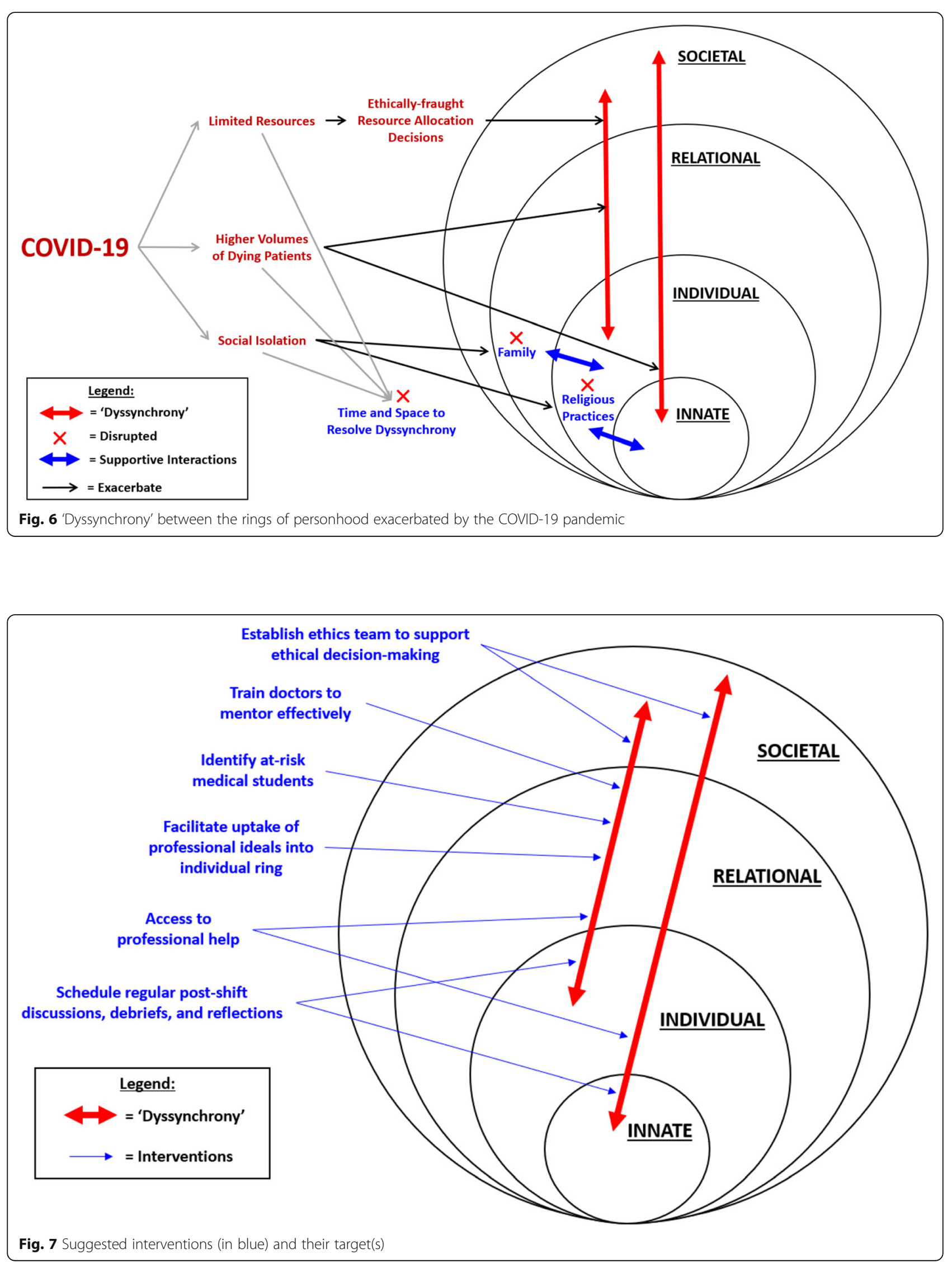
Table 2 Suggested Interventions to Improve Medical Students' Management of Dying Patients

\section{Findings and Problems Faced by Medical Students}

Clinical attachment with direct interaction with dying patients is an effective way to learn [86].

Lack of debrief, death acknowledgement, and closure. Need for psychological support. "Often being 'on their own'" [107]. "Little or no time for discussion or reflection on patient's death" [16, 101, 118]. "Experiencing 'a small form of PTSD' every time he thought of a patient's death for several weeks after it happened, because no one on his team had acknowledged it." [107].

Medical students found it difficult to address and reconcile conflicts in personhood: Dilemma of being professionally detached yet still able to display empathy and care towards patients $[13,87]$. Conflict between personal values and professional ideals. Belief that patients under the having to triage decisions $[24,134,142]$. care of doctors should not die. Conflict between non-maleficence and

Intervention

Integrate direct clinical care of dying patients into mandatory

curriculum [11].Actively encourage interdisciplinary and interprofessional collaborations with nurses, medical social workers, pharmacists and other healthcare professionals who bring with them unique experiences and insights into the care for the dying and their families [137-141]

- Schedule routine [16] reflective discussions (E.g. Focus group discussions) and debriefs $[16,18,21,22,78,89,101]$ with clear guidelines [90], as well as after every death including rounding on those who died. Provide counselling and access to a psychologist to medical students who require more support $[18,21]$. Incorporating death rounds into attachment programs. - Provides an opportunity to explore strong emotions that arise from caring for dying patients with colleagues in a supportive environment.

- Facilitate uptake of professional ideals into individual ring of personhood. - Minimizes 'dyssynchrony' between the rings of personhood leading to newfound self-confidence and empowerment [84]. Incorporate discussions of professionalism in palliative care. Provide advice and standards on how best to calibrate emotional attachment in the care of dying patients, and also to balance seemingly conflicting ideals. Encourage medical students to express any internal conflicts they have during debriefs, death rounds, or privately with a trained mentor. Establish ethics teams to support and be consulted on ethical decision making.

Inconsistent or weak medical student-doctor relationship with lack of support and guidance $[16,22,87,101,102,107]$. Felt seniors were not ideal role models [102]. Gave conflicting accounts of professionalism [102]. Felt disempowered and discouraged from actively participating in the care of the patient $[12,99,102] \cdot$ Some medical students feel uncomfortable approaching superiors for help $[14,16,21,79,101,107]$.

The experiences, reactions, and preferred support systems of medical students to be varied. While some preferred to seek support from within their relational ring $[12,100]$, others preferred to turn to peers and clinicians from their societal ring $[12,14,86,90]$ possibly because of the shared experience amongst members of the medical community $[12,14]$ that made them feel better understood [14].
Train doctors to mentor effectively: Role model skills, such as communication with the dying [78], through explicit demonstrations [12]. Routinely inquire of trainees about their and acknowledge their feelings [16]. Discuss and attend to emotional aspects of death with team [16]. Observe medical students and provide feedback [114]. Provide a standardized guide of professionalism milestones. Provide a safe learning environment. Identify medical students who need support. Train healthcare workers to spot signs of psychological distress in their colleagues.

Adopt a tailored approach to intervention to individualize support for medical students. Ensure different options are available to medical students to help cope. access to professional help and formally integrate debriefs, discussions and reflections into the curriculum structure (Fig. 7). These interventions are expanded upon in Table 2.

\section{Limitations}

This review is not without its limitations. This SSR is limited by articles published in English or with English translations. Hence, much of the data comes from North American and European Western countries or in the English language, skewing perspectives and raising questions as to the applicability of these findings in the setting of other cultures. Whilst databases used were selected by the expert team and the team utilized independent selection processes, some critical papers may still have been omitted. Despite the use of the Split Approach and tabulated summaries which allowed for triangulation and transparency in the direction of the SSR, reviewers' inherent biases could still have an impact on the data analysis. Furthermore, while quality assessment of included articles was conducted using MERSQI and COREQ, we were unable to quality assess all the articles due to the heterogeneity in the methodologies used. While many supportive interventions were identified in this review, this SSR was not designed to assess them. More evidence-based literature reviews are required to examine the effectiveness and extensiveness of supportive interventions. As we used a single model (RToP) to review the impact of death and dying on medical students, imperfections and presumptions from the models are transferred to this review. As such, studies employing other models of personhood can be integrated to support our findings.

\section{Conclusion}

The findings of this SSR in SEBA should be a rallying cry to ensure that medical students are effectively supported. It is clear that support of trained senior 
clinicians who are sensitive to the dilemma and conflicts that students working in a structured and nurturing environment is key in the era of the COVID-19 pandemic and beyond. The silver lining in these unprecedented times may be a chance to correct years of poor preparation. We have much to learn but the adversity posed now may be just the impetus to make the change.

\section{Supplementary Information}

The online version contains supplementary material available at https://doi. org/10.1186/s12909-020-02411-y.

Additional file 1: Appendix A. PubMed Search Strategy

Additional file 2: Appendix B. Summary of Included Articles

\section{Abbreviations}

COVID-19: Coronavirus Disease 2019; SSR: Systematic Scoping Review; NUS: National University of Singapore; YLLSoM: Yong Loo Lin School of Medicine; NCCS: National Cancer Centre Singapore; PCC: Population, Concept and Context; PICOS: Population, Intervention, Comparison, Outcomes, Study Design; RtoP: Ring Theory of Personhood; MERSQI: Medical Education Research Study Quality Instrument; COREQ: Consolidated Criteria for Reporting Qualitative Studies; BEME: Best Evidence Medical Education; STORIES: Structured Approach to the Reporting in Healthcare Education of Evidence Synthesis; PPE: Personal Protective Equipment; SARS: Severe Acute Respiratory Syndrome; PTS: Post Traumatic Stress

\section{Acknowledgements}

The authors would like to dedicate this paper to the late Dr. S Radha Krishna whose advice and ideas were integral to the success of this paper. The authors would like to thank the anonymous reviewers whose advice and feedback greatly improved this manuscript.

\section{Authors' contributions}

CYH, CSK, CHJC, JYL, YHML, SKL, AERH, LHET, NXLL, NCPX, KTYJ, NHAK, CJL, ABHMA, AMCC, YPT, SM, LKRK were involved in data curation, formal analysis, investigation, preparing the original draft of the manuscript as well as reviewing and editing the manuscript. MC, YTO were involved in reviewing and editing the manuscript. All authors have read and approved the manuscript for submission.

\section{Funding}

No funding was received for this review.

\section{Availability of data and materials}

All data generated or analysed during this review are included in this published article [and its supplementary information files].

\section{Ethics approval and consent to participate}

NA

\section{Consent for publication}

NA

\section{Competing interests}

All authors declare no competing interests.

\section{Author details}

${ }^{1}$ Yong Loo Lin School of Medicine, National University of Singapore, 1E Kent Ridge Road, NUHS Tower Block, Level 11, Singapore 119228, Singapore. ${ }^{2}$ Division of Supportive and Palliative Care, National Cancer Centre Singapore, Level 4, 11 Hospital Crescent, Singapore 169610, Singapore. ${ }^{3}$ Lee Kong Chian School of Medicine, Nanyang Technological University, 59 Nanyang Dr, Experimental Medicine Building, Singapore 636921, Singapore. ${ }^{4}$ Division of Cancer Education, National Cancer Centre Singapore, Level 4, 11 Hospital Crescent, Singapore 169610, Singapore. ${ }^{5}$ Medical Library, National University of Singapore Libraries, Blk MD6, Centre, 14 Medical Dr, \#05-01 for
Translational Medicine, Singapore 117599, Singapore. ${ }^{6}$ Star PALS (Paediatric Advanced Life Support), HCA Hospice Care, Kwong Wai Shiu Hospital Singapore, 705 Serangoon Road, Block A \#03-01, Singapore 328127, Singapore. ${ }^{7}$ Department of Family Medicine, Yong Loo Lin School of Medicine, National University of Singapore, 1E Kent Ridge Road, NUHS Tower Block, Level 11, Singapore 119228, Singapore. ${ }^{8}$ Palliative Care Institute Liverpool, Academic Palliative \& End of Life Care Centre, University of Liverpool, Cancer Research Centre, University of Liverpool, 200 London Road, Liverpool L3 9TA, UK. 'Duke-NUS Medical School, 8 College Road, Singapore 169857, Singapore. ${ }^{10}$ Centre of Biomedical Ethics, National University of Singapore, Blk MD11, 10 Medical Drive, \#02-03, Singapore 117597, Singapore. ${ }^{11} \mathrm{PalC}$, The Palliative Care Centre for Excellence in Research and Education, PalC c/o Dover Park Hospice, 10 Jalan Tan Tock Seng, Singapore 308436, Singapore.

Received: 21 May 2020 Accepted: 2 December 2020

Published online: 28 December 2020

\section{References}

1. Mareiniss DP. The impending storm: COVID-19, pandemics and our overwhelmed emergency departments. Am J Emerg Med. 2020;38:12934.

2. Armocida B, Formenti B, Ussai S, Palestra F, Missoni E. The Italian health system and the COVID-19 challenge. Lancet Public Health. 2020;5(5):e253.

3. Miller IF, Becker AD, Grenfell BT, Metcalf $\mathrm{CJ}$. Disease and healthcare burden of COVID-19 in the United States. Nat Med. 2020;26(8):1212-7.

4. BBC. Coronavirus: Hospitals in Brazil's São Paulo 'near collapse'. 2020.

5. Organization WH. Coronavirus disease (COVID-19) Situation Report - 121. Geneva: World Health Organization (WHO); 2020.

6. lacobucci G. Covid-19: medical schools are urged to fast-track final year students. BMJ. 2020;368:m1064

7. Redford G. "Itching to get back in": Medical students graduate early to join the fight: Association of American Medical Colleges; 2020. Available from: https://www.aamc.org/news-insights/itching-get-back-medical-studentsgraduate-early-join-fight. Accessed 21 May 2020.

8. Siddique H. Final-year medical students graduate early to fight Covid-19. United Kingdom: The Guardian; 2020.

9. Uppadhayay I. King's fourth-year medical students graduate early because of COVID-19. London: The King's Tab; 2020.

10. Khamees D, Brown CA, Arribas M, Murphey AC, Haas MR, House JB. In crisis: medical students in the COVID-19 pandemic. AEM Educ Train. 2020;4(3): 284-90.

11. Anderson WG, Williams JE, Bost JE, Barnard D. Exposure to death is associated with positive attitudes and higher knowledge about end-of-life care in graduating medical students. J Palliat Med. 2008;11(9):1227-33.

12. Ratanawongsa N, Teherani A, Hauer KE. Third-year medical students' experiences with dying patients during the internal medicine clerkship: a qualitative study of the informal curriculum. Acad Med. 2005;80(7):641-7.

13. Smith-Han K, Martyn H, Barrett A, Nicholson H. That's not what you expect to do as a doctor, you know, you don't expect your patients to die. Death as a learning experience for undergraduate medical students. BMC Med Educ. 2016;16:108.

14. Pessagno R, Foote C, Aponte R. Dealing with death: medical students' experiences with patient loss. Omega (United States). 2014;68(3):207-28.

15. Hughes TSM, Jacobs-Lawson JM, Arnold S. Confronting death: perceptions of a good death in adults with lung Cancer. Am J Hosp Palliat Med. 2008; 25(1):39-44

16. Rhodes-Kropf J, Carmody SS, Seltzer D, Redinbaugh E, Gadmer N, Block SD, et al. "This is just too awful; I just can't believe I experienced that...": medical student' reactions to their "most memorable" patient death. Acad Med. 2005;80(7):634-40

17. Jacoby $L H$, Beehler $C J$, Balint JA. The impact of a clinical rotation in hospice: medical students' perspectives. J Palliat Med. 2011;14(1):59-64.

18. Masia RT, Basson WJ, Ogunbanjo GA. Emotional reactions of medical doctors and students following the loss of their patients at the Dr George Mukhari hospital emergency unit. South Africa. S Afr Fam Pract. 2010;52(4): 356-63.

19. Bharmal A, Morgan T, Kuhn I, Wee B, Barclay S. Palliative and end-of-life care and junior doctors': a systematic review and narrative synthesis. BMJ Support Palliat Care. 2019;0:1-7. 
20. Gibbins J, McCoubrie R, Forbes K. Why are newly qualified doctors unprepared to care for patients at the end of life? Med Educ. 2011;45(4):389-99.

21. Batley NJ, Bakhti R, Chami A, Jabbour E, Bachir R, El Khuri C, et al. The effect of patient death on medical students in the emergency department. BMC Med Educ. 2017;17(1):110.

22. Wear D. "face-to-face with it": medical students' narratives about their endof-life education. Acad Med. 2002;77(4):271-7.

23. Wallace CL, Wladkowski SP, Gibson A, White P. Grief during the COVID-19 pandemic: considerations for palliative care providers. J Pain Symptom Manag. 2020;60(1):e70-e6.

24. Pfefferbaum B, North CS. Mental Health and the Covid-19 Pandemic. N Engl J Med. 2020;383(6):510-2.

25. Kissler SM, Tedijanto C, Lipsitch M, Grad Y. Social distancing strategies for curbing the COVID-19 epidemic. medRxiv. 2020; Available from https:// www.medrxiv.org/content/medrxiv/early/2020/03/24/2020.03.22.20041079. full.pdf. Cited 2020 Nov 19

26. Wagner RE, Kropiunigg U, Hexel M, Bauer WW. Crying in hospitals: a survey of doctors', nurses' and medical students' experience and attitudes. Med J Aust. 1997;166(1):13-6.

27. Munn Z, Peters MDJ, Stern C, Tufanaru C, McArthur A, Aromataris E. Systematic review or scoping review? Guidance for authors when choosing between a systematic or scoping review approach. BMC Med Res Methodol. 2018;18(1):143.

28. Colquhoun HL, Levac D, O'Brien KK, Straus S, Tricco AC, Perrier L, et al. Scoping reviews: time for clarity in definition, methods, and reporting. J Clin Epidemiol. 2014;67(12):1291-4.

29. Tricco AC, Lillie E, Zarin W, O'Brien $K$, Colquhoun H, Kastner M, et al. A scoping review on the conduct and reporting of scoping reviews. BMC Med Res Methodol. 2016;16:15.

30. Horsley T. Tips for improving the writing and reporting quality of systematic, scoping, and narrative reviews. J Contin Educ Heal Prof. 2019; 39(1):54-7.

31. Kow CS, Teo YH, Teo YN, Chua KZY, Quah ELY, Kamal N, et al. A systematic scoping review of ethical issues in mentoring in medical schools. BMC Med Educ. 2020;20(1):246

32. Bok C, Ng CH, Koh JWH, Ong ZH, Ghazali HZB, Tan LHE, et al. Interprofessional communication (IPC) for medical students: a scoping review. BMC Med Educ. 2020;20(1):372.

33. Ngiam LXL, Ong YT, Ng JX, Kuek JTY, Chia JL, Chan NPX, et al. Impact of caring for terminally ill children on physicians: a systematic scoping review. Am J Hosp Palliat Care. 2020;0(0):1049909120950301.

34. Krishna LKR, Tan LHE, Ong YT, Tay KT, Hee JM, Chiam M, et al. Enhancing mentoring in palliative care: an evidence based mentoring framework. J Med Educ Curric Dev. 2020;7:2382120520957649.

35. Kamal NHA, Tan LHE, Wong RSM, Ong RRS, Seow ERW, Loh EKY, et al. Enhancing education in palliative medicine: the role of systematic scoping reviews. Palliat Med Care: Open Access. 2020;7(1):1-11.

36. Ong RRS, Seow REW, Wong RSM, Loh EKY, Kamal NHA, Mah ZH, et al. A systematic scoping review of narrative reviews in palliative medicine education. Palliat Med Care: Open Access. 2020;7(1):1-22.

37. Mah ZH, Seow REW, Loh EKY, Kamal NHA, Ong RRS, Tan LHE, et al. A systematic scoping review of systematic reviews in palliative medicine education. Palliat Med Care: Open Access. 2020;7(1):1-12.

38. Chua WJ, Cheong CWS, Lee FQH, Koh EYH, Toh YP, Mason S, Krishna LKR. Structuring mentoring in medicine and surgery. A systematic scoping review of mentoring programs between 2000 and 2019. J Contin Educ Heal Prof. 2020;40(3):158-68.

39. Ng YX, Koh ZYK, Yap HW, Tay KT, Tan XH, Ong YT, et al. Assessing mentoring: a scoping review of mentoring assessment tools in internal medicine between 1990 and 2019. PLoS One. 2020;15(5):e0232511.

40. Pring R. The 'false dualism' of educational research. J Philos Educ. 2000;34(2): 247-60.

41. Crotty M. The foundations of social research: meaning and perspective in the research process. Thousand Oaks: Sage; 1998.

42. Ford DW, Downey L, Engelberg R, Back AL, Curtis JR. Discussing religion and spirituality is an advanced communication skill: an exploratory structural equation model of physician trainee self-ratings. J Palliat Med. 2012;15(1): 63-70.

43. Schick-Makaroff K, MacDonald M, Plummer M, Burgess J, Neander W. What synthesis methodology should I use? A review and analysis of approaches to research synthesis. AIMS Public Health. 2016;3(1):172.
44. Peters MD, Godfrey CM, Khalil H, Mclnerney P, Parker D, Soares CB. Guidance for conducting systematic scoping reviews. Int J Evid Based Healthc. 2015;13(3):141-6.

45. Peters MD, Godfrey CM, Mclnerney P, Soares CB, Khalil H, Parker D. The Joanna Briggs institute reviewers' manual 2015: methodology for JBI scoping reviews; 2015.

46. Pham MT, Rajić A, Greig JD, Sargeant JM, Papadopoulos A, McEwen SA. A scoping review of scoping reviews: advancing the approach and enhancing the consistency. Res Synth Methods. 2014;5(4):371-85.

47. Sambunjak D, Straus SE, Marusic A. A systematic review of qualitative research on the meaning and characteristics of mentoring in academic medicine. J Gen Intern Med. 2010;25(1):72-8.

48. Tan YS, Teo SWA, Pei Y, Sng JH, Yap HW, Toh YP, et al. A framework for mentoring of medical students: thematic analysis of mentoring programmes between 2000 and 2015. Adv Health Sci Educ Theory Pract. 2018;23(4):671-97.

49. Wong G, Greenhalgh T, Westhorp G, Buckingham J, Pawson R. RAMESES publication standards: meta-narrative reviews. BMC Med. 2013;11(1):20.

50. Popay J, Roberts H, Sowden A, Petticrew M, Arai L, Rodgers M, Britten N, Roen K, Duffy S. Guidance on the conduct of narrative synthesis in systematic reviews. A product from the ESRC methods programme. Lancaster: Lancaster University. 2006;10(2.1):1018-4643.

51. Braun V, Clarke V. Using thematic analysis in psychology. Qual Res Psychol. 2006;3(2):77-101.

52. Boyatzis RE. Transforming qualitative information: thematic analysis and code development. Thousand Oaks: Sage; 1998.

53. Sawatsky AP, Parekh N, Muula AS, Mbata I, Bui T. Cultural implications of mentoring in sub-Saharan Africa: a qualitative study. Med Educ. 2016;50(6): 657-69.

54. Voloch KA, Judd N, Sakamoto K. An innovative mentoring program for Imi Ho'ola Post-Baccalaureate students at the University of Hawai'i John A. Burns School of Medicine. Hawaii Med J. 2007:66(4):102.

55. Cassol H, Pétré B, Degrange S, Martial C, Charland-Verville V, Lallier F, Bragard I, Guillaume M, Laureys S. Qualitative thematic analysis of the phenomenology of near-death experiences. PLoS One. 2018;13(2):e0193001.

56. Stenfors-Hayes T, Kalén S, Hult H, Dahlgren LO, Hindbeck H, Ponzer S. Being a mentor for undergraduate medical students enhances personal and professional development. Med Teach. 2010;32(2):148-53.

57. Hsieh HF, Shannon SE. Three approaches to qualitative content analysis. Qual Health Res. 2005;15(9):1277-88.

58. Elo S, Kyngäs H. The qualitative content analysis process. J Adv Nurs. 2008; 62(1):107-15.

59. Mayring P. Qualitative content analysis. Companion Qual Res. 2004;1(2004): 159-76.

60. Baldwin C, Chandran L, Gusic M. Guidelines for evaluating the educational performance of medical school faculty: priming a national conversation. Teach Learn Med. 2011;23(3):285-97.

61. Sambunjak D, Straus SE, Marušić A. Mentoring in academic medicine: a systematic review. JAMA. 2006:296(9):1103-15.

62. Radha Krishna LK, Alsuwaigh R. Understanding the fluid nature of personhood-the ring theory of personhood. Bioethics. 2015;29(3):171-81.

63. Radha Krishna LK. Accounting for personhood in palliative sedation: the ring theory of personhood. Med Humanit. 2014;40(1):17-21.

64. Krishna LK. Personhood within the context of sedation at the end of life in Singapore. BMJ Case Rep. 2013;2013:bcr2013009264.

65. Krishna LK, Alsuwaigh R, Miti PT, Wei SS, Ling KH, Manoharan D. The influence of the family in conceptions of personhood in the palliative care setting in Singapore and its influence upon decision making. Am J Hosp Palliat Care. 2014;31(6):645-54.

66. Krishna LK, Kwek SY. The changing face of personhood at the end of life: the ring theory of personhood. Palliat Support Care. 2015;13(4):1123-9.

67. Radha Krishna LK, Murugam V, Quah DS. The practice of terminal discharge: is it euthanasia by stealth? Nurs Ethics. 2018;25(8):1030-40.

68. Ho ZJ, Krishna LK, Yee CP. Chinese familial tradition and Western influence: a case study in Singapore on decision making at the end of life. J Pain Symptom Manag. 2010;40(6):932-7.

69. Krishna LK, Yong CY, Koh SM. The role of palliative rehabilitation in the preservation of personhood at the end of life. Case Reports. 2014;2014: bcr2014204780

70. Alsuwaigh R, Krishna LK. The compensatory nature of personhood. Asian Bioeth Rev. 2014;6(4):332-42. 
71. Krishna LK, Te Tay J, Watkinson DS, Yee AC. Advancing a welfare-based model in medical decision. Asian Bioeth Rev. 2015;7(3):306-20.

72. Alsuwaigh R. How do English-speaking Cancer patients conceptualise personhood? Ann Acad Med Singap. 2015;44(6):207-17.

73. Sim SW, Krishna LKR. Respecting the wishes of incapacitated patients at the end of life. Ethics Med. 2016;32(1):15-29.

74. Chang MK, Lim MX, Tay K, Lee RJ, Sim DS, Menon S, Kanesvaran R, Puvanendran R, Krishna LK. The influence of evolving confucian beliefs in the selection of proxy decision-makers at the end of life in Singapore. Asian Bioethics Review. 2017;9(1-2):117-28.

75. Moher D, Liberati A, Tetzlaff J, Altman DG. Preferred reporting items for systematic reviews and meta-analyses: the PRISMA statement. Ann Intern Med. 2009;151(4):264-9.

76. Kimball B. On healing: a medical student's lessons from hospice. Patient Educ Couns. 2017;100(6):1240-1.

77. Spencer R. A piece of my mind. Portrait of an artist. JAMA. 2013;309(6):557-8.

78. Stecho W, Khalaf R, Prendergast P, Geerlinks A, Lingard L, Schulz V. Being a hospice volunteer influenced medical students' comfort with dying and death: a pilot study. J Palliat Care. 2012;28(3):149-56.

79. Mohd Slim MA. The superhero mythos: a medical student's experience of death. J Palliat Med. 2013;16(7):803-5.

80. Shunkwiler SM, Broderick A, Stansfield RB, Rosenbaum M. Pilot of a hospicebased elective to learn comfort with dying patients in undergraduate medical education. J Palliat Med. 2005;8(2):344-53.

81. Mott ML, Gorawara-Bhat R, Marschke M, Levine S. Medical students as hospice volunteers: reflections on an early experiential training program in end-of-life care education. J Palliat Med. 2014;17(6):696-700.

82. Hsieh C, Arenson CA, Eanes K, Sifri RD. Reflections of medical students regarding the care of geriatric patients in the continuing care retirement community. J Am Med Dir Assoc. 2010;11(7):506-10.

83. Mutto E, Cavazzoli C, Argemi J, Tambone V, Centeno C, Villar M. Teaching dying patient Care in Three Universities in Argentina, Spain, and Italy. J Palliat Med. 2009;12:603-7.

84. Boland JW, Dikomitis L, Gadoud A. Medical students writing on death, dying and palliative care: a qualitative analysis of reflective essays. BMJ Support Palliat. 2016;6(4):486-92.

85. Kearsley JH, Lobb EA. "it is not a disease we treat, but a person": medical students' reflections on their first rotations to an oncology and palliative care unit. J Palliat Care. 2013;29(4):232-6.

86. Gadoud A, Adcock Y, Jones L, Koon S, Johnson M. It's not all doom and gloom: perceptions of medical students talking to hospice patients. J Palliat Med. 2013:16(9):1125-9.

87. Kelly E, Nisker J. Medical students' first clinical experiences of death. Med Educ. 2010;44(4):421-8

88. Nguyen AP. How palliative care transformed my perspective of medicine. J Palliat Med. 2011;14(2):244.

89. Crawford GB, Zambrano SC. Junior doctors' views of how their undergraduate clinical electives in palliative care influenced their current practice of medicine. Acad Med. 2015;90(3):338-44

90. Jones R, Finlay F. Medical students experience of paediatric deaths. Arch Dis Child. 2010;95:A21

91. Schwartz CE, Clive DM, Mazor KM, Ma Y, Reed G, Clay M. Detecting attitudinal changes about death and dying as a result of end-of-life care curricula for medical undergraduates. J Palliat Med. 2005;8(5):975-85.

92. MacLeod RD, Parkin C, Pullon S, Robertson G. Early clinical exposure to people who are dying: learning to care at the end of life. Med Educ. 2003;37(1):51-8.

93. Udeshi S, Mohess D. Palliative medicine: a medical Student's perspective. Palliat Med. 2018;21(1):107.

94. Hebblewhite A. A medical student's reflection on palliative care: managing emotional connection with patients. Palliat Support Care. 2015;13(2):405-8.

95. Harvey A. Preconceptions in palliative care: a medical student's perspective. J Palliat Med. 2013;16(9):1152-3.

96. Baumrucker $\mathrm{SJ}$, Woods $\mathrm{S}$. The personal side of hospice and palliative care education. Am J Hosp Palliat Care. 2000;17(2):80-2.

97. Morell EA. Learning that a death can be a good death. J Palliat Med. 2012; 15(2):248-9.

98. Henderson AK. The perfect hospice patient. Am J Hosp Palliat Care. 2004; 21(5):389-94.

99. Kuczewski MG, McCarthy MP, Michelfelder A, Anderson EE, Wasson K, Hatchett L. "I will never let that be ok again": student reflections on competent spiritual care for dying patients. Acad Med. 2014;89(1):54-9.
100. Block SD, Billings JA. Learning from the dying. N Engl J Med. 2005;353(13): 1313-5.

101. Jones R, Finlay F. Medical students' experiences and perception of support following the death of a patient in the UK, and while overseas during their elective period. Postgrad Med J. 2014;90(1060):69-74.

102. Baker M, Wrubel J, Rabow MW. Professional development and the informal curriculum in end-of-life care. J Cancer Educ. 2011;26(3):444-50.

103. Liao J. A matter of the heart. Ann Intern Med. 2011;155(10):716.

104. Goldberg G, Gliatto P, Karani R. Effect of a 1-week clinical rotation in palliative medicine on medical school Graduates' knowledge of and preparedness in caring for seriously ill patients. J Am Geriatr Soc. 2011;59: 1724-9.

105. Vallurupalli M. Mourning on morning rounds. N Engl J Med. 2013;369(5): 404-5.

106. Frank J. Refusal: deciding to pull the tube. J Am Board Fam Pract. 2010; 23(5):671-3

107. Fernandes R, Shore W, Muller JH, Rabow MW. What it's really like: the complex role of medical students in end-of-life care. Teach Learn Med. 2008;20(1):69-72.

108. Minor S, Kashan S, Castillo M. A team reacts to a Patient's death. Fam Med. 2015;47(10):813-4.

109. Pestinger M, Bouteleux M, Radbruch L, Elsner F. The patient as a teacher-the meaning of death and dying for medical students. Palliat Med. 2010;24(4): S149.

110. Billings ME, Engelberg R, Curtis J, Block S, Sullivan AM. Determinants of medical students' perceived preparation to perform end-of-life care, quality of end-of-life care education, and attitudes toward end-of-life care. J Palliat Med. 2010;13(3):319-26.

111. Carmody SS, Arnold RM, Wohnsiedler J, Schuh R, Barnard D. Attitudes of medical students toward working with dying patients. J Gen Intern Med. 2002;17:221-2

112. Bertao C, Kayashima R, Braun K. Perceptions of a required hospice experience: a comparison of first- and fourth-year medical students. Hawaii Med J. 2003:62:100-3.

113. Cripe LD, Hedrick DG, Rand KL, Burns D, Banno D, Cottingham A, et al. Medical Students' professionalism narratives reveal that experiences with death, dying, or palliative care are more positive than other experiences during their internal medicine clerkship. Am J Hosp Palliat Care. 2017;34(1): 79-84.

114. Stepanyan K, Weiss T, Pessegueiro A, Pietras C. Lessons from the development and implementation of a palliative care elective for fourth-year medical students: a pilot study. Am J Hosp Palliat Care. 2020;37(3):191-5.

115. Kriesen U, Altiner A, Mueller-Hilke B. Perception of bedside teaching within the palliative care setting-views from patients, students and staff members. Ann Palliat Med. 2018;7(4):411-9.

116. Borgstrom E, Cohn S, Barclay S. Medical professionalism: conflicting values for tomorrow's doctors. J Gen Intern Med. 2010;25(12):1330-6.

117. Kavas MV, Oztuna D. Thanatophobia in medical students: approach to death and dying patients attitude scale (ADDPAS) for undergraduate years in medicine. J Cancer Educ. 2011;26(4):774-81.

118. Gillett K, O'Neill B, Bloomfield J. Factors influencing the development of end-of-life communication skills: a focus group study of nursing and medical students. Nurse Educ Today. 2016:36:395-400.

119. Haig A, Dozier M. BEME guide no 3: systematic searching for evidence in medical education--part 1: sources of information. Med Teach. 2003;25(4): 352-63.

120. Gordon M, Gibbs T. STORIES statement: publication standards for healthcare education evidence synthesis. BMC Med. 2014;12(1):143.

121. Reed DA, Beckman TJ, Wright SM, Levine RB, Kern DE, Cook DA. Predictive validity evidence for medical education research study quality instrument scores: quality of submissions to JGIM's medical education special issue. J Gen Intern Med. 2008:23(7):903-7.

122. Tong A, Sainsbury P, Craig J. Consolidated criteria for reporting qualitative research (COREQ): a 32-item checklist for interviews and focus groups. Int J Qual Health Care. 2007;19(6):349-57.

123. Victoria Loguinova-Yakovleva MK. Russia medical students slam 'forced labour' in coronavirus wards. Paris: AFP News Agency; 2020.

124. Khasawneh Al, Humeidan AA, Alsulaiman JW, Bloukh S, Ramadan M, AlShatanawi TN, et al. Medical students and COVID-19: Knowledge, attitudes, and precautionary measures. A descriptive study from Jordan. Front Public Health. 2020;8:253 
125. Agarwal V, Gupta L, Davalbhakta S, Misra D, Agarwal V, Goel A. Undergraduate medical students in India are underprepared to be the young-taskforce against Covid-19 amid prevalent fears. medRxiv. [Preprint] 2020. Available from: https://doi.org/10.1101/2020.04.11.20061333.

126. Nguyen HT, Do BN, Pham KM, Kim GB, Dam HT, Nguyen TT, et al. Fear of COVID-19 scale-associations of its scores with health literacy and healthrelated behaviors among medical students. Int J Environ Res. 2020;17(11): 4164.

127. Hjiej G, Fourtassi M. Medical students' dilemma during the Covid-19 pandemic; between the will to help and the fear of contamination. Med Educ Online. 2020;25(1):1784374.

128. Gallagher TH, Schleyer AM. "We signed up for this!"- -student and trainee responses to the COVID-19 pandemic. N Engl J Med. 2020;382:e96

129. Spoorthy MS, Pratapa SK, Mahant S. Mental health problems faced by healthcare workers due to the COVID-19 pandemic-a review. Asian J Psychiatr. 2020;51:102119.

130. Liu Q, Luo D, Haase JE, Guo Q, Wang XQ, Liu S, et al. The experiences of health-care providers during the COVID-19 crisis in China: a qualitative study. Lancet Glob Health. 2020;8(6):e790-8.

131. Reger MA, Stanley $\mathrm{H}$, Joiner TE. Suicide mortality and coronavirus disease 2019-a perfect storm? JAMA Psychiatry. 2020;77(11):1093-4.

132. Chiew TG. COVID-19: Guarding against burnout, compassion fatigue and trauma in frontline healthcare workers. Singapore: CNA; 2020.

133. Lai J, Ma S, Wang Y, Cai Z, Hu J, Wei N, et al. Factors associated with mental health outcomes among health care workers exposed to coronavirus disease 2019. JAMA Netw Open. 2020:3(3):e203976.

134. Maves RC, Downar J, Dichter JR, Hick JL, Devereaux A, Geiling JA, et al. Triage of scarce critical care resources in COVID-19 an implementation guide for regional allocation: an expert panel report of the task force for mass critical care and the American College of Chest Physicians. Chest. 2020;158(1):212-25.

135. Adams JG, Walls RM. Supporting the health care workforce during the COVID-19 global epidemic. JAMA. 2020;323(15):1439-40.

136. Chong MY, Wang WC, Hsieh WC, Lee CY, Chiu NM, Yeh WC, et al. Psychological impact of severe acute respiratory syndrome on health workers in a tertiary hospital. Br J Psychiatry. 2004;185:127-33.

137. Black D, Hardoff D, Nelki J. Educating medical students about death and dying. Arch Dis Child. 1989;64(5):750.

138. Jain A, Luo E, Yang J, Purkiss J, White CJAM. Implementing a nurseshadowing program for first-year medical students to improve interprofessional collaborations on health care teams. Acad Med. 2012;87(9): $1292-5$.

139. Field MJ, Cassel CK. Approaching death: improving care at the end of life. Washington, D.C.: National Academies Press; 1997.

140. Bissell LE. Why and how pharmacists should get involved in medical education. Evaluation. 2020;14(47):19.

141. Egelund EF, Gannon J, Motycka C, Smith WT, Kraemer DF, Solomon KH. A simulated approach to fostering competency in end-of-life care among pharmacy students. Am J Pharm Educ. 2019;83(4):6904.

142. Greenberg N, Docherty M, Gnanapragasam S, Wessely S. Managing mental health challenges faced by healthcare workers during covid-19 pandemic BMJ. 2020;368:m1211.

\section{Publisher's Note}

Springer Nature remains neutral with regard to jurisdictional claims in published maps and institutional affiliations.

Ready to submit your research? Choose BMC and benefit from:

- fast, convenient online submission

- thorough peer review by experienced researchers in your field

- rapid publication on acceptance

- support for research data, including large and complex data types

- gold Open Access which fosters wider collaboration and increased citations

- maximum visibility for your research: over $100 \mathrm{M}$ website views per year

At BMC, research is always in progress.

Learn more biomedcentral.com/submissions 